\title{
Milbenallergie entwickelt sich wie eine Lawine
}

\author{
Forscher haben die molekularen Ursprünge der Hausstaub- \\ milbenallergie entdeckt.
}

Wissenschaftler der Charité Universitätsmedizin Berlin haben herausgefunden, welche Moleküle der Hausstaubmilbe die primären Ziele des Immunsystems sind, wenn Kinder eine allergische Rhinitis und Asthma entwickeln [1].

Die Forscher untersuchten die Daten und Blutproben von 722 in Deutschland lebenden Kindern, die als Teilnehmer der Multizentrischen Allergiestudie seit ihrem Geburtstag im Jahr 1990 über 20 Jahre hinweg regelmäßig an Befragungen und Untersuchungen teilgenommen haben, so die Mitteilung der Charité Berlin.

\section{Milben-Proteine nanotechnolo- gisch untersucht}

Proteine der Hausstaubmilbe dienten in Kombination mit nanotechnologi-

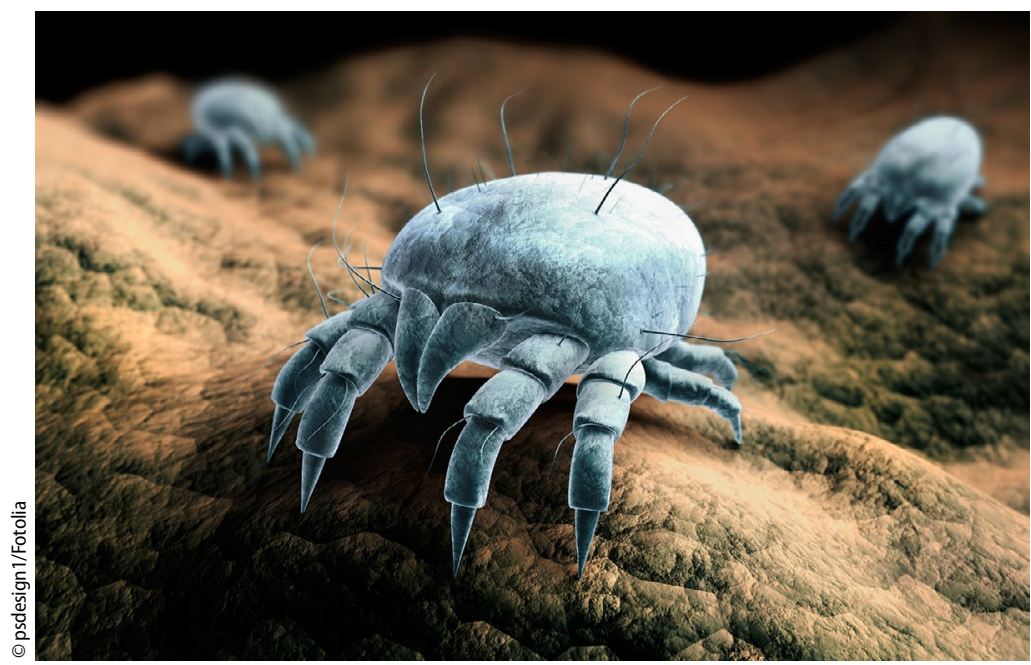

$\Delta$ Hausstaubmilben sind etwa 0,1 bis 0,5 mm groß und weiß. Ihr Körper trägt haarförmige Borsten schen Methoden dazu, die Ursprünge und Entwicklung der Immunantwort von der Kindheit bis hin zum jungen Erwachsenen zu charakterisieren.

Die Wissenschaftler entdeckten, dass bereits im Blut von Vorschulkindern Antikörper gegen drei Hausstaubmilbenmoleküle mit der Bezeichnung "Der $p 1{ }^{\prime \prime}$, ,Der $p 2$ " und "Der $p 23$ " gemessen werden konnten, oft bevor sich die Erkrankung überhaupt klinisch zeigte, heißt es weiter.

Bei einigen Kindern folgte eine sogenannte "Sensibilisierungskaskade“, die sich nach und nach gegen weitere Milbenmoleküle richtet und als "molecular spreading" bezeichnet wird.

\section{Antikörperbildung entscheidend} Kinder, die Antikörper gegen eine Vielzahl von Molekülen bildeten, hatten ein höheres Risiko, im Laufe ihres Lebens an allergischer Rhinitis und Asthma zu erkranken.

Auf der anderen Seite entwickelten Kinder, die schon in sehr jungen Jahren erste Antikörper gebildet hatten und bei denen ein oder beide Elternteile an Heuschnupfen litten, mit einer höheren Wahrscheinlichkeit eine Allergie. Hinzu kam, dass gesunde Vorschulkinder, die bereits Antikörper gegen die beiden Moleküle „Derp 1"oder "Derp 23" hatten, häufiger Asthma im Schulalter entwickelten.

„Die Hausstaubmilbenallergie entwickelt sich in der Kindheit wie eine Lawine. Sie beginnt früh mit nur einem oder sehr wenigen Molekülen und umfasst im weiteren Verlauf ein immer breiteres Molekülspektrum", wird Erstautorin Dr. Daniela Posa zitiert.

Und Posa weiter: „Je breiter die Streuung der molekularen Sensibilisierung ist, desto höher ist das Risiko Asthma zu entwickeln." Die Forscher sind davon überzeugt, dass diese Erkenntnisse neue Perspektiven in der Prävention und Therapie der Hausstaubmilbenallergie eröffnen.

\footnotetext{
Literatur

1. Posa D et al (2017) Evolution and predictive value of $\mathrm{lg} E$ responses toward a comprehensive panel of house dust mite allergens during the first 2 decades of life. J Allergy Clin Immunol 139(2):541-549.e8. doi:10.1016/j. jaci.2016.08.014
}

Paediatr. Paedolog. Austria 2017 · 52:77 DOI 10.1007/s00608-017-0463-3

() Springer-Verlag Wien 2017 